\title{
Direct Electronic Load Control for Demand Response in a DC Microgrid Using a Virtual Internal Impedance Screening Model and PID Controller
}

\author{
Chia-Hung Lin ${ }^{1}$ Jian-Liung Chen ${ }^{2}$. Chao-Lin Kuo ${ }^{3}$. Long-Yi Chang ${ }^{1}$
}

Received: 28 June 2017 / Accepted: 27 February 2018 / Published online: 13 March 2018

(C) Springer Nature Singapore Pte Ltd. 2018

\begin{abstract}
To reduce peak loads, direct and indirect load control are common strategies used to change demand during peak hours. Voltage dependent demand response (DR) is a direct load control for changing loads in a DC mircogrid. The characteristics of electronic loads can be controlled with a switch-mode DC boost or buck converter. They have faster response to maintain stable output voltage under the fluctuating load condition and heavy load condition. Applying a fast load step to voltage regulator can maintain a well regulated voltages and load currents. The increased load resistance will cause voltage drop when load current is increased during heavy loads. Thus, their adjustable internal load impedances can change the absorbed currents by regulating the duty ratio. In this study, a screening model is employed to estimate the virtual internal impedances of power electronic loads. Then, the desired duty ratio can be determined to perform the DR program, while the boost converter acts to step-up or step-down the load voltages using the PID (proportional-integral-derivative) controller. For a DC microgrid, simulation results show the feasibility of the proposed methods: (1) exact control of load voltage at both the power source side and load sides and (2) regulation of absorbed currents to modify load voltages and reduce line voltage drops and line losses during heavy loads.
\end{abstract}

Keywords Demand response · Direct load control · Virtual internal impedance · Power electronic load · Proportional-integral-derivative controller

\section{Introduction}

Power electronic loads are used in DC or AC microgrids and distribution networks, such as naval ships,

Chia-Hung Lin

eechl53@gmail.com

Jian-Liung Chen

t20047@cc.kyu.edu.tw

Chao-Lin Kuo

clkuo@mail.nkmu.edu.tw

Long-Yi Chang

lychang@mail.ncut.edu.tw

1 Department of Electrical Engineering, National Chin-Yi University of Technology, Taiping District, Taichung City, 41170, Taiwan

2 Department of Electrical Engineering, Kao-Yuan University, Kaohsiung City, 82151, Taiwan

3 Department of Maritime Information and Technology, National Kaohsiung University of Science and Technology, Cijin District, Kaohsiung City, 80543, Taiwan plug-in hybrid electric vehicle charging stations, industrial systems, and smart buildings / houses. DC microgrids have no frequency and reactive power controls and have a good interface connection with the main grid and renewable energy sources, energy storage devices, and power electronic loads [1-3]. In a DC microgrid, renewable energy sources, energy storage devices, and electronic loads can be directly connected without AC-DC converters. DC distributed generations (DGs), such as in photovoltaic (PV) energy, wind power, and fuel cells, and power electronic loads are connected with DC bus via the DC-DC converters. Therefore, energy storage and power electronic loads are easy to control the variable demands and to balance the DC DGs. A DC microgrid can also operate in a standalone mode as a single aggregated system with DGs, and can meet the local demands without requiring long transmission lines. Because DC power is sent near the demand site, thus transmitted DC power can increase the efficiency as comparing with AC based microgrids. DGs can be easily integrated into an entire DC power source to supply local loads [4, 5], while line losses and line voltage drops 
can be decreased. In addition, the microgrid is also connected to the main grid through a bidirectional AC-DC converter. The grid-connected mode is required to be available for local demands during peak hours or DGs blackout. Hence, power stability and uninterruptible power supply can be further improved. Traditionally, regular loads are usually constant powers and constant impedances. During peak hours, energy mediators or aggregators [6-8] allow the demand response (DR) programs to directly switch off the uncontrolled and lower priority loads, or indirectly control the loads using contractual and intensive DR strategies [9-11]. With the increasing usages of power electronic loads, these loads are supplied with the DC-DC converters. Therefore, a power electronic load with the switch-mode converter is a variable impedance load [12-14] and can be controlled to affect the power absorption from the DG sources, such as PV energy, wind energy, and battery energy storage $[15,16]$. We need to develop a DC DR to adjust the internal parameters of power electronic loads during peak hours [17-19]. For direct load control in DC microgrid, an aggregator integrates a DR and DGs to adjust the controllable power electronic load, according to the collections of each load current and voltage. Hence, a screening model is designed to estimate the desired effective impedance and duty ratio of power electronic loads with the load voltages and currents. Then, the aggregator announces the desired effective impedance to each load for performing the DR. Finally, each load will be adjusted the duty ratio of DCDC converter accordingly by the controller [15]. Therefore, this study intends to propose a virtual internal impedance screening model to determine the effective impedance. Each power electronic load will adjust the duty ratio of DC-DC converter that participates the DR program using the PID controller. Therefore, the proposed method can keep power balance in a DC microgrid by absorbing power from DGs during peak hours.

Power electronic loads are connected with the PWM (pulse-width modulation) DC-DC converters and DC-AC inverters in DC microgrids or AC distribution networks [4, $17,20,21]$. DGs can synchronously store energy in the storage devices and supply DC or AC loads. One advantage is that their internal load characteristics can be controlled as variable resistor loads in a DC microgrid and variable impedances in an AC microgrid [17, 22, 23]. When heavy current occurs at the load, the voltage at the load bus will drop due to line resistance and internal impedance of the DC-DC converter or DC-AC inverter. We can control the variable resistors for the power electronic loads. Therefore, absorbed powers from the DGs can be regulated by switchmode converters with PWM controls in a DC microgrid To reduce the DG supply variations, DC-DC boost converters modulate the absorbed powers by increasing the load voltages through the duty ratio regulation [24]. The adopted range (0.95 - 1.05 in per-unit value) of load voltages can be fixed or adjustable by using the variable resistors to set the desired load voltage Under the AMI (Advanced Metering Infrastructure) environment, distributed information can be available to synthesize direct load control with adjusting the effective impedance of power electronic load. Therefore, each load can be adjusted to control the power absorption from DG sources and modify the load voltage for achieving the DR program.

In order to reduce the voltage drops and power absorption a screening model need to be incorporated to estimate the internal load impedance. In this study, a voltage dependent DR strategy will be used to directly control power electronic loads during heavy loading These power electronic loads are supplied with the DC-DC converter. Therefore, each power electronic load is equivalent to a variable resistor load. Its equivalent impedance is the correlation with the internal impedance, including the impedance of a converter and static load resistor. The virtual internal impedance screening model, a key technique, is proposed to estimate the effective impedance of power electronic loads during peak hours. Its screening model is derived from nodal voltage equations, Newton-Raphson method, and DC power flow [25-27]. Nodal voltage equations are used to model the whole DC microgrid and to express the variable resistor of each power electronic load. Therefore, the "virtual internal impedance" is a screening model in term of the voltages to estimate the equivalent impedance of each power electronic load. The virtual internal impedance can be estimated using the whole nodal voltages from the online metering voltages in a DC microgrid. While the metering nodal voltages changes, the estimated virtual internal impedance is sensitively used to identify the heavy loads during peak hours. A DC power flow with the current injection method [27] and the Newton-Raphson method $[25,26]$ is employed to validate the proposed screening model. Therefore, the equivalent impedance of each power electronic load can be measured and directly controlled at the common coupling point. By controlling the variable resistor of power electronic loads, the power absorption delivered to each electronic load can be regulated while participates in DR. The duty ratio deviation is determined to adjust the boost converter by using the voltage conditions within its maximum and minimum permissible duty ratios. When the load voltages exceed the critical threshold values, $0.95-1.05$ in per-unit value, the desired duty ratio is estimated to adjust the boost converter through the controller. The proposed screening model and controller scheme intend to perform the direct load control, while modify the load voltage at each load and reduce the power loss on each distribution feeder.

PI, PID, and fuzzy-PID controllers [28-30] can regulate the duty ratio to the desired operating point of a DCDC converter or a DC-AC inverter. However, a limitation 
of PI and PID controllers is that you need to tune the controller parameters to improve the control performance to meet various operating conditions. Fuzzy-based control methods can automatically tune the controller parameters. However, these methods require the design of inference rules or a look-up table for the determination of the controller parameters. Therefore, a Ziegler-Nicholas-based [30-32] tuning method is used to design the three control parameters, including proportional $(\mathrm{P})$, integral (I), and derivative (D) gains. This avoids the trial-anderror design procedure, minimizes overshoot, improves transient responses, decreases steady-state errors, and improves control performances. In addition, self-tuning based optimization methods [33, 34] are also used to determine the optimal control parameters to improve control performance and transient responses, such as particle swarm optimization-PID, evolutionary programming-fuzzy control, and genetic algorithm-PI. However, these methods are used only to tune the optimal control parameters, but they can not estimate the desired duty ratio of $\mathrm{f}$ a converter or an inverter. Based on direct load control mode, the switch-mode converters with PWM controls are suffice to regulate power electronic loads for DR program. The proposed "virtual internal impedance" screening model with a tuned PID controller can achieve the intended DR aim. For a DC microgrid, simulation results show that the proposed methods can act on the DR program to reduce demand and that exact load voltages can be accurately regulated in a specific range. The proposed screening model and control scheme can also be easily implemented in an embedded system or an intelligent/a smart meter.

The remainder of this paper is organized as follows. Section "Methodology" describes the methodology, including the DC microgrid model, virtual internal impedance screening model, PID controller, and the procedure of electronic load DR. Sections "Simulation Results and Discussions" and "Conclusion" present simulation results, discussions, and conclusion demonstrating the efficiency of the proposed methods and conclusions, respectively.

\section{Methodology}

\section{Microgrid Model}

A DC microgrid has a radial configuration comprising distributed energy sources, distribution feeders, storage devices, and local communication systems. It can be connected to the main grid through an AC-DC converter at the point of common coupling. For regular DC loads, demands, such as PV energy, small-scale wind energy, and storage devices, come directly from the distributed energy sources at a DC bus. The PV output power and voltages are easily influenced by atmospheric conditions such as temperature, solar radiation, rain, and moderate-to-heavy cloud cover. The maximum power point tracking (MPPT) algorithm is used to estimate the maximum output power and maximum power point voltage (MPPV) [35-38]. The lumped output current, $I_{S}$, and lumped output power, $P_{S}$, for a PV array with $p$ identical PV panels connected in parallel can be expressed as follows:

Lumped Current: $I_{S}=I_{1}+I_{2}+\cdots+I_{p}$,

$I_{S}=p \times\left(N_{p} I_{L}-N_{p} I_{s a t}\left[\exp \left(\frac{q}{k T A} \frac{V}{N_{s}}\right)-1\right]\right)$

Lumped Output: $P_{S}=V_{S} \times I_{S}$

where $V_{S}$ is the output voltage, $I_{L}$ the photocurrent, $I_{\text {sat }}$ the reverse saturation current, $N_{p}$ the number of modules connected in parallel, $N_{s}$ the number of modules connected in series, $q$ the charge of an electron, $k$ Boltzmann's constant, $A$ the diode quality factor, $1<A<2$ ( $A=1$ being the ideal value), and $T$ the cell temperature. Then, the MPPT algorithm is used to regulate the PV array's output power and voltage. The MPPV, $V_{S}$, can be estimated as follows $[35,36]$ :

$V=\frac{N_{s} k T A}{q} \ln \left(\frac{p N_{p} I_{L}+p N_{p} I_{\text {sat }}-I}{p N_{p} I_{\text {sat }}}\right)$

$I_{L}=\left[I_{s c}+k_{s c}\left(T-T_{r}\right)\right] \frac{S}{100}, \quad V_{S}=V+\eta \times\left(T-T_{r}\right)$

where $T_{r}$ is the reference temperature $\left(25^{\circ} \mathrm{C}\right), I_{s c}$ is the cell short-circuit current at $T_{r}, k_{s c}$ is the short-circuit current/ temperature coefficient, $S$ the solar radiation value, and $\eta$ is the temperature compensation coefficient. Considering Taiwan's environment and weather, solar radiation of 0.4$1.0 \mathrm{~kW} / \mathrm{m}^{2}$ and temperature of $20^{\circ} \mathrm{C}-35^{\circ} \mathrm{C}$ in outer places, the characteristic curves of a PV array with four $(p=4)$ identical PV panels are shown in Fig. 1. In our previous studies $[35,36]$ the MPPT algorithm was used to estimate the maximum output power and MPPV under various solar radiation and temperature conditions. It can be seen that as these atmospheric conditions increase, the PV array output power gradually increases. Hence, the exact voltages of DC loads can be regulated by the DC-DC converters at the common coupling point [8], as shown in Fig. 1a. No phase angle, frequency, or reactive power has to be considered for control.

When available energy sources cannot meet the demand, DR strategies act to reduce peak load demands during peak 
Fig. 1 The PV array

characteristic curves. a The I-V

curves under various solar radiation and temperature, $\mathbf{b}$ The

$\mathrm{P}-\mathrm{V}$ curves under various solar radiation and temperature (a)

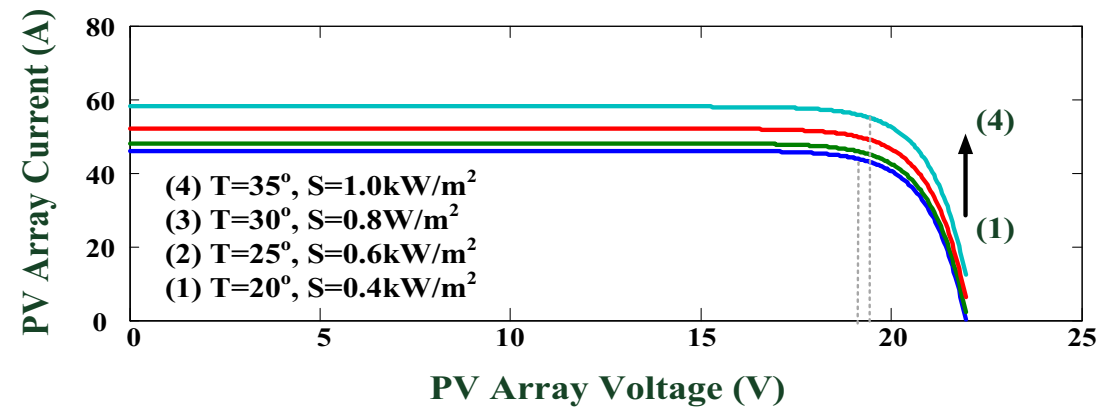

(b)

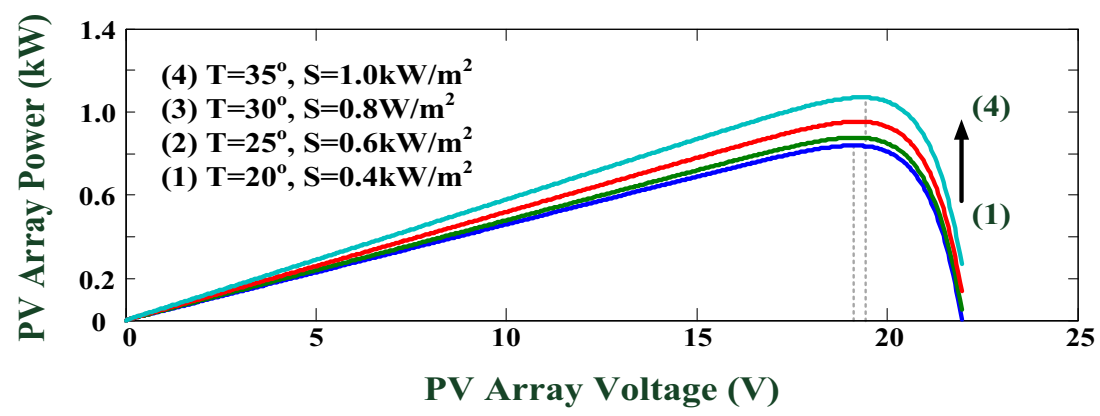

hours; these include incentive control, direct load control, and indirect load control [8,9]. For a distributed supply system, DC voltage is a local variable for voltage dependent DR. By metering the bus voltages, DR program acts when the voltage exceeds critical threshold values, $(0.95,1.05)$ per unit value, such as load voltages drop due to load demand increases, voltage drops on distribution feeders, and power loss increases. Therefore, we propose the equivalent impedance, as a variable impedance, to control the load voltage and power demands from the distributed energy source to each power electronic load. Each power electronic load can be modeled with a DC-DC converter, that is, the virtual impedance, $R_{i}$, can be controlled to change the internal impedance of an electronic load [17, 20, 21]

$R_{i}=(1-D)^{2} R_{0}$

where $R_{i}$ is the virtual load impedance of an electronic load (equivalent impedance), $R_{O}$ is the rated load impedance, and $D \in(0,1)$ is the duty ratio of the DC-DC converter. A boost converter (voltage level: 24VDC at the common coupling point, 48VDC at the load bus) is considered in this study, as seen in Fig. 2a. Thus, the virtual load impedance will be used to identify the load changes, and then intend to change power delivery to each electronic load.

In addition, the "DC power flow" can be used to rapidly analyze local information, including the bus (nodal) voltages and power delivery to each power electronic load.
As seen in Fig. 2b, considering a radial distribution network with $n$ nodes, the whole DC microgrid has the following admittance matrix, $Y$ :

$$
\begin{aligned}
& M_{j i}=\frac{1}{R_{j i}}, \quad j=1,2, \ldots, n, i=0,1,2, \ldots, n \\
& y_{j j}=M_{j i}, \quad j \neq 0, i=0 \\
& y_{j k}=\left\{\begin{array}{l}
\left(M_{j j}+\sum_{k \neq j}^{n} M_{j k}\right. \\
-M_{j k}, \text { if } j \neq k, \text { if } j=k
\end{array}\right.
\end{aligned}
$$

$Y=\left[y_{j k}\right] \in R^{n \times n}, \quad j=1,2, \ldots, n, k=1,2, \ldots, n$

where element, $y_{j k}$, is the admittance $\left(y_{j j} \neq 0\right)$ between the nodes $j$ and $k$. Using the current injection method [20], the current source is injected into the DC microgrid, the PV output power is injected into node $1 \#$, and the nodal voltage equations are as follows:

$Y V=I \Rightarrow[Y]_{n \times n}\left[\begin{array}{c}V_{1} \\ V_{2} \\ V_{3} \\ \vdots \\ V_{n}\end{array}\right]_{n \times 1}=\left[\begin{array}{c}I_{S} \\ 0 \\ 0 \\ \vdots \\ 0\end{array}\right]_{n \times 1}$ 

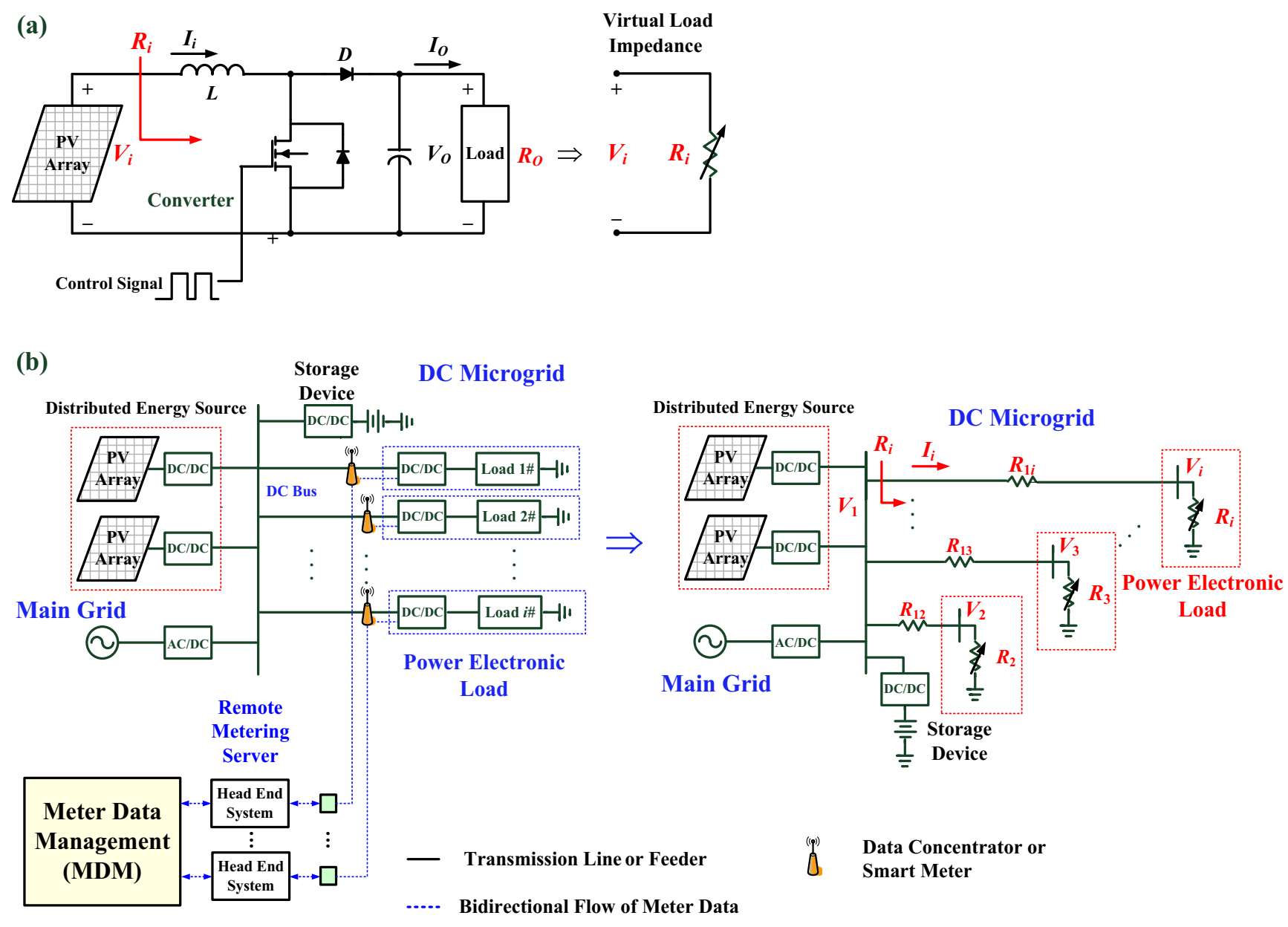

Fig. 2 The virtual load impedance in a DC microgrid. a The virtual impedance model with a variable resistor for a power electronic load, b The multiple virtual impedances in a DC microgrid

$$
\begin{gathered}
{\left[\begin{array}{ccccc}
y_{11} & y_{12} & y_{13} & \cdots & y_{1 n} \\
y_{21} & y_{22} & y_{23} & \cdots & y_{2 n} \\
y_{31} & y_{32} & y_{33} & \cdots & y_{3 n} \\
\vdots & \vdots & \vdots & \ddots & \vdots \\
y_{n 1} & y_{n 2} & y_{n 3} & \cdots & y_{n n}
\end{array}\right]\left[\begin{array}{c}
V_{1} \\
V_{2} \\
V_{3} \\
\vdots \\
V_{n}
\end{array}\right]=\left[\begin{array}{c}
I_{S} \\
0 \\
0 \\
\vdots \\
0
\end{array}\right]} \\
I_{i}\left(V_{i}\right)=y_{i 1} V_{i}+y_{i 2} V_{2}+\cdots+y_{i i} V_{i}+\cdots y_{i n} V_{n}
\end{gathered}
$$

where $I_{S}$ is the injection current into node $1 \#$, depending on realistic overall loads; $I_{i}\left(V_{i}\right)$ is the $i$ th nodal voltage equation; and $V_{i}$, where $i=1,2, \ldots, n$, is the $i$ th guess. Thus, nodal voltages, $V_{1}-V_{n}$, can be calculated using iteration methods [25, 26]. In this study, the NewtonRaphson method uses the value of $V_{i}(p)$ at iteration $p$ to generate $V_{i}(p+1)$ as follows:

$$
J_{i} V_{i}(p+1)=J_{i} V_{i}(p)+\left(I-I_{i}\left(V_{i}\right)\right), \quad J_{i}=\frac{\partial I_{i}\left(V_{i}\right)}{\partial V_{i}}
$$

Jacobian (J) matrix: $J=\left[\begin{array}{ccccc}\frac{\partial I_{1}}{\partial V_{1}} & \frac{\partial I_{1}}{\partial V_{2}} & \frac{\partial I_{1}}{\partial V_{3}} & \cdots & \frac{\partial I_{1}}{\partial V_{n}} \\ \frac{\partial I_{2}}{\partial V_{1}} & \frac{\partial I_{2}}{\partial V_{2}} & \frac{\partial I_{2}}{\partial V_{3}} & \cdots & \frac{\partial I_{2}}{\partial V_{n}} \\ \frac{\partial I_{3}}{\partial V_{1}} & \frac{\partial I_{3}}{\partial V_{2}} & \frac{\partial I_{3}}{\partial V_{3}} & \cdots & \frac{\partial I_{3}}{\partial V_{n}} \\ \vdots & \vdots & \vdots & \ddots & \vdots \\ \frac{\partial I_{n}}{\partial V_{1}} & \frac{\partial I_{n}}{\partial V_{2}} & \frac{\partial I_{n}}{\partial V_{3}} & \cdots & \frac{\partial I_{n}}{\partial V_{n}}\end{array}\right]=Y$ 
The iteration operation uses the value of $V_{i}(p)$ at iteration number, $p$, to generate voltage, $V_{i}(p+1)$. The iterative computing procedure is terminated when the following convergent condition, $\varepsilon$, is achieved:

$$
\left|\frac{V_{i}(p+1)-V_{i}(p)}{V_{i}(p)}\right| \leq \varepsilon \text {, for all } i=1,2,3, \ldots, 10
$$

When any metering nodal voltage change exceeds critical threshold values, the proposed screening model is employed to estimate the virtual internal impedance. In this Study, the DC power flow using the current injection and NewtonRaphson method is employed to validate the screening results for on line applications. The presence of computing results enhance the screening confidences of heavy load identification. A virtual impedance model of the electronic load is derived in next section.

\section{Virtual Internal Impedance Screening Model}

Considering $n$ power electronic loads, $i=2,3,4, \ldots, n$, each power electronic load is equivalent to a variable resistor load, $R_{i}$, as seen in Fig. 2b. The distributed energy source is modeled as a constant voltage source, $V_{s}$, with a constant internal resistor, $R_{S}$, at Bus $1 \#$. Hence, one current source is injected into the DC microgrid, and the nodal voltage equations at the Bus $i \#$ are as follows:

$\frac{V_{i}}{R_{i}}+\frac{V_{i}-V_{1}}{R_{i 1}}=0$

$\frac{V_{1}-V_{s}}{R_{s}}+\frac{V_{1}-V_{i}}{R_{i 1}}+\sum_{k=2, k \neq i}^{n} \frac{V_{1}-V_{k}}{R_{1 k}}=0$

where $V_{1}$ is the nodal voltage at bus $1 \# ; R_{i}$, where $i=2$, $3, \ldots, n$, is the virtual load impedance at bus $i \#$; and $R_{i 1}=R_{1 i}$ and $R_{1 k}=R_{k 1}\left(y_{1 k}=y_{k 1}\right)$ are the feeder resistors. Combining the nodal voltage (15) and (11), each power electronic load's internal impedance can be derived as follows:

$$
\begin{aligned}
& \frac{V_{i}}{R_{i}}=\frac{V_{s}-V_{1}}{R_{S}}+\sum_{k=2, k \neq i}^{n} \frac{V_{k}-V_{1}}{R_{1 k}} \\
& \Rightarrow R_{i}=\frac{V_{i}}{\left(\frac{V_{s}-V_{1}}{R_{s}}\right)+\left(\sum_{k=2, k \neq i}^{n} y_{1 k} \times\left(V_{k}-V_{1}\right)\right)} \\
& I_{i}\left(V_{k}\right) \approx\left(\frac{V_{s}-V_{1}}{R_{S}}\right)+\left(\sum_{k=2, k \neq i}^{n} y_{1 k} \times\left(V_{k}-V_{1}\right)\right) \\
& V_{k}=\frac{1}{y_{k k}}\left[I_{k}-\left(y_{1 k} V_{k}+y_{2 k} V_{k}+\cdots+y_{n k} V_{k}\right)\right], \quad k=2,3,4, \ldots, n
\end{aligned}
$$

where $I_{i}$ and $V_{k}$ are the load current and voltage of $i$ th power electronic load. Therefore, the internal impedance of $i$ th power electronic load can be estimated. Then, the boost DC-DC converter can be regulated to support the DR by the duty ratio. Let $D_{i}^{\min }$ and $D_{i}^{\max }$ denote the minimum and maximum duty ratios at the $i$ th power electronic load, as [17]

$$
\begin{aligned}
D_{i}^{\min } \leq D_{i} \leq D_{i}^{\max } & \Rightarrow D_{i}^{\min }-D_{i} \leq 0 \leq D_{i}^{\max }-D_{i} \\
& \Rightarrow \Delta D_{i}^{-} \leq 0 \leq \Delta D_{i}^{+}
\end{aligned}
$$

Thus, Eq. 22 can be represented as the constraint,

$\Delta R_{i}^{-} \leq 0 \leq \Delta R_{i}^{+} \Rightarrow R_{i}^{-}-R_{i o} \leq 0 \leq R_{i}^{+}-R_{i o}$

where

$$
\begin{aligned}
R_{i}^{-} & =\left(1-\Delta D_{i}^{-}\right)^{2} R_{i 0} \quad \Rightarrow \quad \Delta D_{i}^{-}=1-\sqrt{\frac{R_{i}^{-}}{R_{i o}}}, \\
\Delta D_{i}^{-} & \geq 0, R_{i}^{-} \leq R_{i o} \\
R_{i}^{+} & =\left(1-\Delta D_{i}^{+}\right)^{2} R_{i 0} \quad \Rightarrow \quad \Delta D_{i}^{+}=1-\sqrt{\frac{R_{i}^{+}}{R_{i o}}} \\
\Delta D_{i}^{+} & <0, R_{i}^{+}>R_{i o}
\end{aligned}
$$

where $R_{i o}$ is the rated load impedance at bus $i \#$. When the current of power electronic load, $I_{i}$, increases, the load voltage, $V_{i}$, decreases below the $<0.95 \mathrm{pu}$ critical threshold. Thus, the virtual load impedance, $R_{i} \approx V_{i} / I_{i}$, can be estimated as $R_{i}^{-}<R_{i o}$ and $\Delta D_{i}^{-}>0$ at the peak hours or heavy load. Then, a controller acts to regulate the duty ratio as follows:

$D_{i, \text { new }}=D_{i, \text { old }}+\Delta D_{i}^{-}$

$D_{i, \text { new }}=D_{i, \text { old }}-\Delta D_{i}^{+}$

where symbol "+" indicates a step-up voltage and "-" a step-down voltage. The duty ratio is always positive and less than $1, D \in(0,1)$. In this study, we propose a tuned PID controller to regulate the duty ratio of the boost converter.

As seen in Fig. 2b, intelligent/smart meters are used to gather information about voltages, currents, and powers in a DC microgrid. In AMI environment, head end systems are specialized software for connecting the meter data management (MDM) system and intelligent/smart meters. Metering data from each consumer allows a power utility to perform the DR program, including direct load control, indirect load control, and incentive control during peak hours. Hence, power utility can deliver commanded messages for controlling smart appliances with remote switches in each consumer. The AMI can also provide available information for DR, including the load profiles, voltages, and currents [10, 38]. By the combining the automatic direct load control method, the proposed "virtual internal impedance screening model" is employed to 
estimate the effective impedance of power electronic loads during peak hours with the load voltages and currents. When the load voltage drop is sensed, the boost converter increases the duty ratio to adjust the internal impedance, and the absorbed current will decrease to meet the DR. This can maintain well regulated voltage to control the power absorption for each electronic load during peak hours.

\section{Regulate Duty Ratio with PID Controller}

The available ranges of load voltage and absorb power are shown in Fig. 3a. Although the load voltage is less than the critical threshold $0.95 \mathrm{pu}$, DG supply power can increase the voltage using the available active power with the power limit, $\left[P_{\min }, P_{\max }\right]$. Conversely, when the demands exceed the DG output power, they can absorb active power from the main grid and / or the controller and can act to control load via voltage dependent DR. To regulate the duty ratio, a PID controller is used to step-up or step-down the output voltage of the boost converter by varying the $\pm \Delta D$. The controller can continuously estimate the errors as the differences between the desired set point, $D_{\text {inew }}$ and the estimated variable, $D_{\text {iest }}$. The controller intends to minimize the error, $e(t)$, by the PID operations [28-30]:

$u(t)=K_{P} e(t)+K_{I} \int_{0}^{t} e(\tau) d \tau+K_{D} \frac{d e(t)}{d t}$

$e(t)=D_{i, \text { new }}(t)-D_{i, \text { est }}(t)$

where $K_{P}$ is the proportional gain, $K_{I}$ is the integral gain, and $K_{D}$ is the derivative gain. The duty ratio regulation with the PID controllerbased scheme is shown in Fig. 3b. Their coefficients are tuning parameters, tuned with the Ziegler-Nicholas method [30-32]. According to the desired step response curve, as seen in Fig. 4 , the rising time, $T_{2}$, is the time when the output response reaches $50 \%$ of the steadystate value, and the derivative gain, $K_{D}$ is $K_{P} \times\left(T_{2}-\right.$ $\left.T_{1}\right)$. The steady state error is removed with the integral gain action, $K_{I}=K_{P} / k_{1}$, where $k_{1}$ is the steadystate value. The design of the controller parameters for the Ziegler-Nicholas step response method is shown in Table 1. The continuous (18) can be modified as the discrete representation

$u\left(t_{h}\right)=K_{P}\left[e\left(t_{h}\right)\right]+K_{I}\left[\sum_{i=1}^{h} e\left(t_{i}\right) \Delta t\right]+K_{D}\left[\frac{e\left(t_{h}\right)-e\left(t_{h-1}\right)}{\Delta t}\right]$

where $\Delta t=t_{h}-t_{h-1}$ is the sampling time, $e\left(t_{h}\right)$ and $e\left(t_{h-1}\right)$ are the errors, $h=0,1,2, \ldots$ That is, the discrete PID controller can be easily implemented in a PC-based application or an embedded system. Equation (20) is used to regulate the duty ratio of a boost $\mathrm{DC}-\mathrm{DC}$ converter in this study.

\section{The Procedure of Electronic Load Demand Responses}

Considering a DC microgrid, a radial distribution configuration with 5 electronic loads (Load 1\# -Load 5\#) and 1 constant load (Load 6\#) is shown in Fig. 5. The power
Fig. 3 The control scheme of the boost dc-dc converter. a The available ranges of load voltage versus the absorb power, $\mathbf{b}$ The duty ratio regulation with the PID controller based scheme (a)

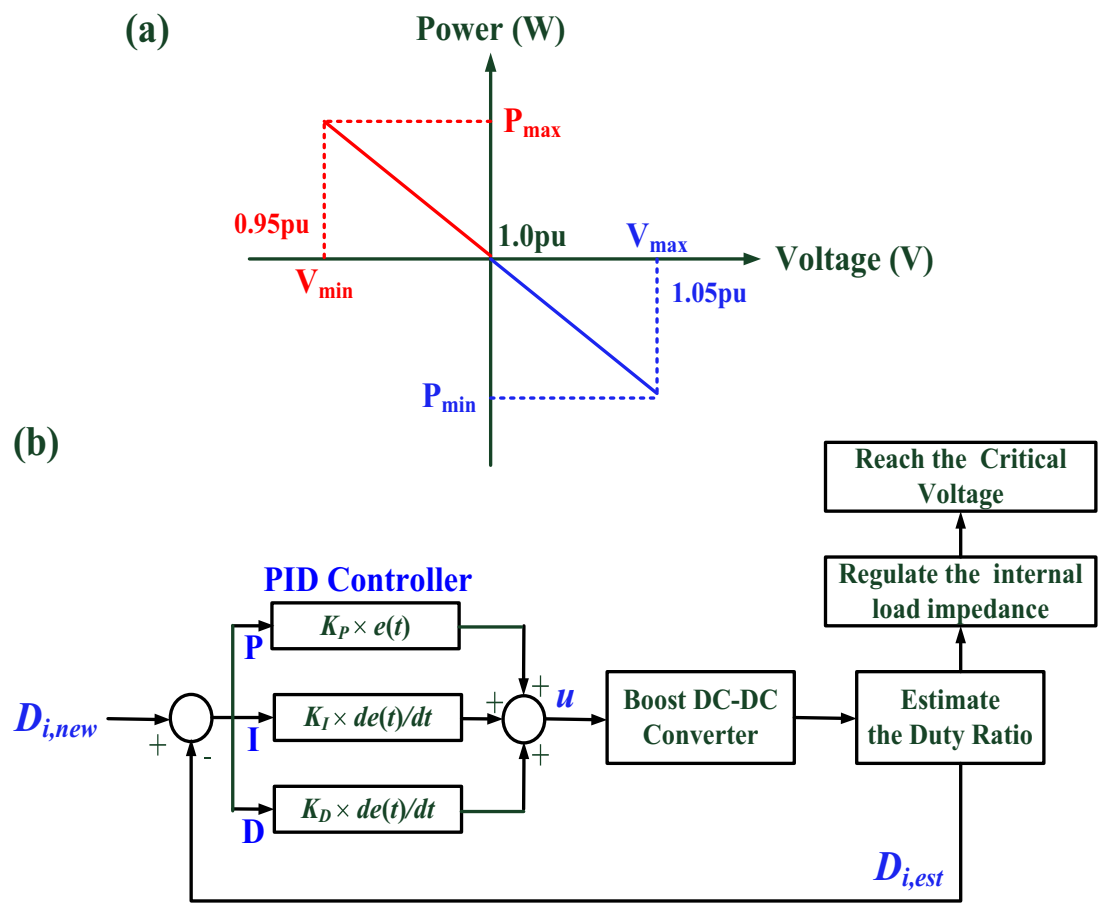

(b) 


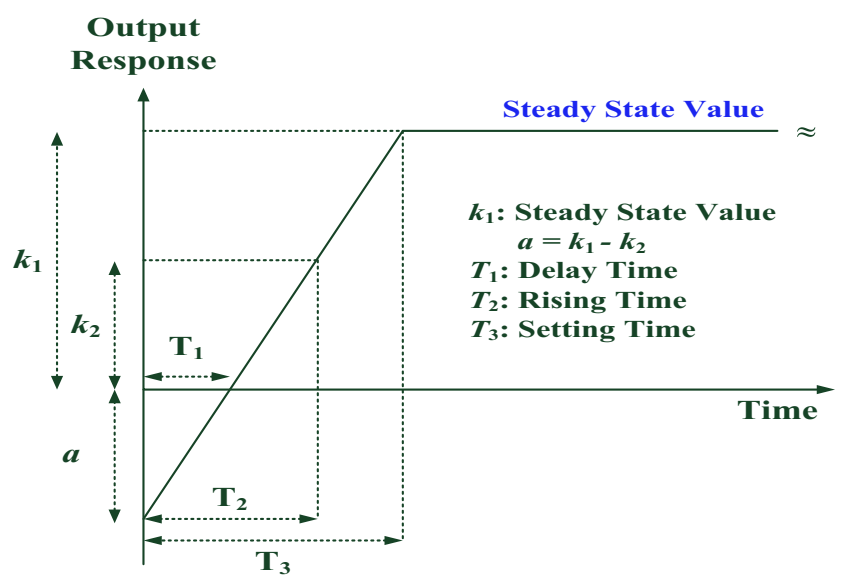

Fig. 4 The step response curve of the close loop control

source resistor, line resistors, and load internal resistors are represented as per unit value in the equivalent circuit. This microgrid can be controlled as a single aggregated system with a DC power source and 6 loads. A PV array with 4 identical PV panels at the bus $1 \#$ is modeled as a constant DC power source. The MPPT algorithm is used to estimate the MPPV, 19.09-19.36VDC, and maximum output power, $0.84-1.07 \mathrm{~kW}$, with temperatures in the range $20^{\circ} \mathrm{C}-35^{\circ} \mathrm{C}$ and solar radiation $0.40-1.00 \mathrm{~kW} / \mathrm{m}^{3}$. For six boost DC-DC converters at the source and load sites, the duty ratio can be estimated to match the load or battery charge to the PV array $[33,34,39,40]$

$D_{S}=1-\frac{M P P V}{V_{L}}, \quad 0<D_{s}<1$

definition of duty ratio:

$D=\frac{t_{o n}}{t_{o n}+t_{o f f}}=\frac{t_{o n}}{T_{d}}$

where the ranges of duty ratio are about from 0.2 (rated load voltage, $V_{L}=24 \mathrm{VDC}$ ) to 0.50 (rated load voltage, $V_{L}=48 \mathrm{VDC}$ ), and $t_{\text {off }}$ the turn-off time and $t_{\text {on }}$ the turn-on time, $T_{d}=t_{o f f}+t_{\text {on }}$ [39]. Therefore, the exact voltages of the DC power source can be fixed under the various atmospheric conditions. In contrast with the $\mathrm{AC}$ power source, only rate voltages, 24VDC or 48VDC, had to be fixed in the specific range, $(0.95 \mathrm{pu}, 1.05 \mathrm{pu})$, without

Table 1 Controller parameter selections for Ziegler-Nicholas step response method

\begin{tabular}{|c|c|c|c|}
\hline Controller $\quad$ Gain & $K_{P}$ & $K_{I}$ & $K_{D}$ \\
\hline $\mathrm{P}$ & $k_{1} / 2$ & - & - \\
\hline P-I & $k_{1} / 2$ & $K_{P} / k_{1}$ & \\
\hline P-D & $k_{1} / 2$ & - & $K_{P} \times\left(T_{2}-T_{1}\right)$ \\
\hline P-I-D & $k_{1} / 2$ & $K_{P} / k_{1}$ & $K_{P} \times\left(T_{2}-T_{1}\right)$ \\
\hline
\end{tabular}

regulating the phase angles, frequencies, reactive power, and synchronizations. Local system reliability and efficiency can be improved. The virtual internal impedance screening model is used to estimate the load changes of each power electronic load. By controlling the variable resistors of each electronic load, $R_{2}$ to $R_{6}$, the absorbed power delivery can be regulated from the DC power source. Regulating the duty ratio, a PID controller is used to tune the voltage level at each bus, $2 \#$ to $6 \#$, while the voltage drops and power losses on each line can be reduced. The voltage dependent DR can be achieved using Eq. 27. The absorbed currents (per unit) and voltage drops for each electronic load are

$I_{1 j}=\left[\left(V_{1}-V_{j}\right) \times y_{1 j}\right], \quad j=2,3, \ldots, 6$

$\Delta V_{1 j}=V_{1, n o r}-V_{j}<0.05 p u$

where $V_{1, \text { nor }}$ is the bus voltage under normal conditions. The DC power flow using the current injection method and Newton-Raphson method can rapidly screen the conditions of the whole grid with cloud computing. When the load voltage is less than the critical value, the voltage dependent DR acts to regulate the internal impedance of power electronic load. Figure 6 shows the procedure for electronic load DR using the proposed methods.

\section{Simulation Results and Discussions}

The proposed virtual internal impedance screening model and PID controller were designed and tested on a PC with MATLAB mathematical computing software (MathWorks Natick, Massachusetts, USA). A small-scale PV array with 4 identical panels (rated voltage: 24VDC, rated power: $1 \mathrm{~kW}$ ) was simulated as a DC power source. The ICM based MPPT algorithm was employed to match the load demands (electronic loads or vehicles) and battery charges. In Taiwan's subtropical outdoor environment, the average solar radiation in outer space is approximately $0.4-0.80$ $\mathrm{kW} / \mathrm{m}^{2}$ and temperature $2{ }^{\circ} \mathrm{C}-30{ }^{\circ} \mathrm{C}$. The $\mathrm{P}-\mathrm{V}$ and $\mathrm{I}-\mathrm{V}$ characteristic curves of the PV array are shown in Fig. $7 \mathrm{a}$ and $b$, respectively As solar radiation and temperature increase, the MPPT algorithm can be used to control the boost converter until the rated voltages reach the desired values, as seen in the duty ratio regulations in Fig. $7 \mathrm{c}$ Therefore, a constant DC power source could be fixed to deliver power to 6 loads under various atmospheric conditions. The virtual internal impedance screening and electronic load DRs were validated as detailed below.

\section{The Results of Virtual Internal Impedance Screening}

For a DC microgrid as in Fig. 5, DC power flow analysis was used to simulate the normal load and heavy load using 


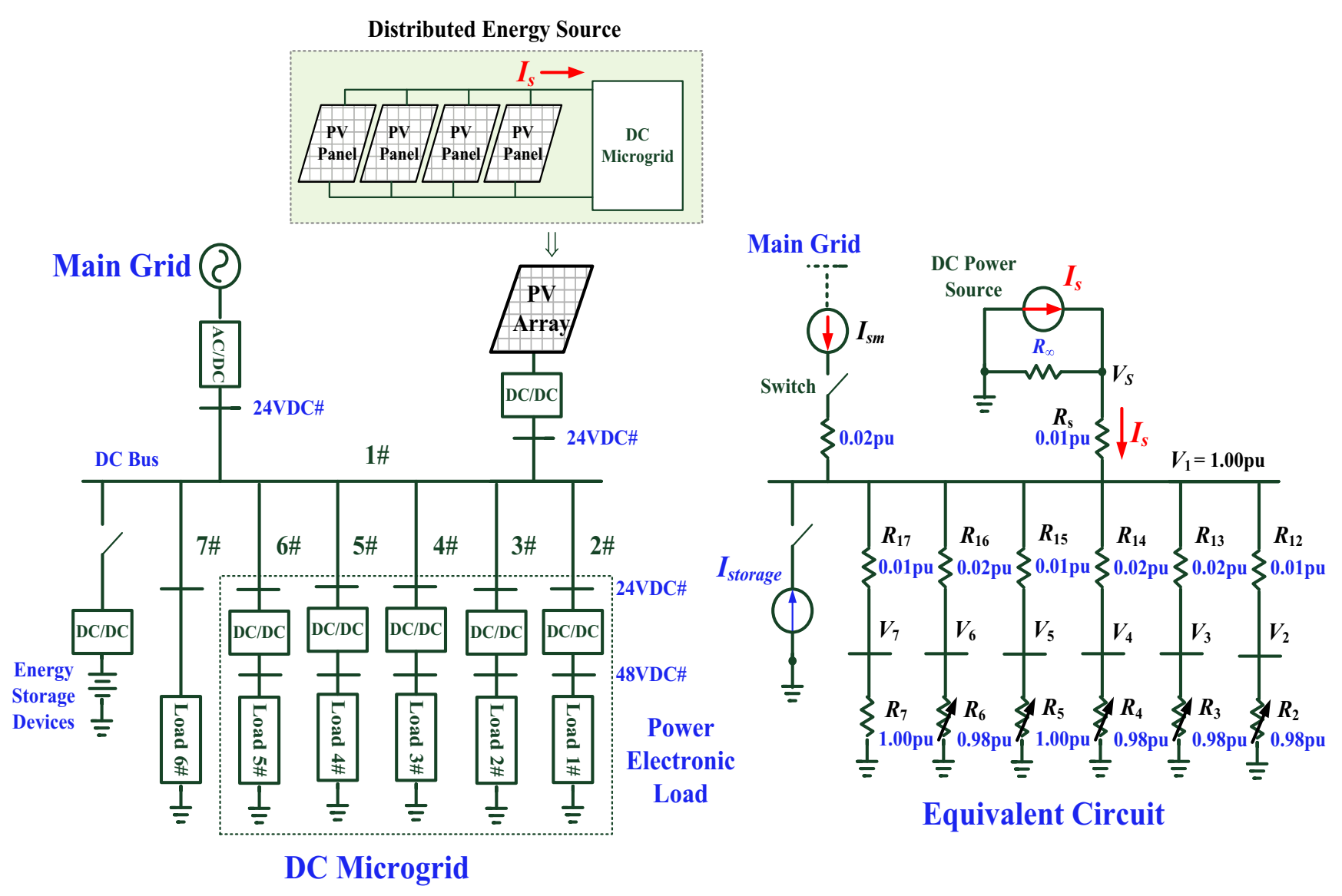

Fig. 5 The configuration of a DC radial distribution network

the current injection and Newton-Raphson methods, as seen by the bus voltages and absorbed load currents in Fig. 8a and b. With a supposed demand increase on the power electronic loads, $1 \#$ to $3 \#$, at busses, $2 \#$ to $4 \#$, the bus voltages drop at each load bus due to absorbed load current and line voltage drop increases. While the load voltages were below the critical threshold value, $0.95 \mathrm{pu}$, the proposed virtual impedance model was employed to estimate the internal load changes, as shown in Fig. 8c. It can be seen that the internal impedances had large deviations at busses 2\#, 3\#, and $4 \#$ (red dash line). The procedure for the virtual internal impedance estimation was as follows:

Step 1) obtain the microgrid parameters, including the injection current, line resistors, and load internal resistors, then perform the DC power flow to obtain whole nodal voltages in a DC microgrid

Step 2) obtain the load voltages as seen in Fig. 8a and identify the voltage levels,

Step 3) estimate the virtual internal impedances as the voltage level was less than $0.95 \mathrm{pu}$.
It can be seen that the original internal impedances were $R_{2}=0.98 \mathrm{pu}, R_{3}=0.98 \mathrm{pu}, R_{4}=0.98 \mathrm{pu}, R_{5}=1.00 \mathrm{pu}$, and $R_{6}=0.98 \mathrm{pu}$. Without regulating the boost converters, the load voltages had deviations, $\left[\Delta V_{12}, \Delta V_{13}, \Delta V_{14}, \Delta V_{15}\right.$, $\left.\Delta V_{16}, \Delta V_{17}\right]=[0.0488,0.0589,0.0589,0.0475,0.0574$, 0.0568] per unit value, and the absorbed load currents gathered at the 2\#, 3\#, and $4 \#$ busses. The estimated virtual internal impedances were computed using Eqs. 18 and 19, as $\left[R_{2}, R_{3}, R_{4}, R_{5}, R_{6}, R_{7}\right]=\left[0.88^{*}, 0.90^{*}, 0.90^{*}\right.$, $1.00,0.97,1.00]$ in Fig. 8c. The absorbed load currents could be computed using Eq. 20 , as $\left[I_{2}, I_{3}, I_{4}, I_{5}, I_{6}\right.$, $\left.I_{7}\right]=\left[1.0809^{*}, 1.0457^{*}, 1.0457^{*}, 0.9525,0.9718,0.9432\right]$ per unit value, during peak hours. Thus, the power electronic loads, $1 \#$ to $3 \#$, were required to regulate by the DC-DC boost converters (24VDC/48VDC). The regulated values of duty ratios were estimated using Eq. 24 , as $\left[\Delta D_{2}^{-}, \Delta D_{3}^{-}\right.$, $\left.\Delta D_{4}^{-}, \Delta D_{5}^{-}, \Delta D_{6}^{-}\right]=\left[0.0524^{*}, 0.0417^{*}, 0.0417^{*}, 0.0000\right.$, $0.0051]$. In this study, no critical loads needed to switch off when the voltage sagged during the heavy load. Voltage dependent DR was used to directly control the loads and to change the absorbed currents to each power electronic load using the boost converters. After the direct load control 


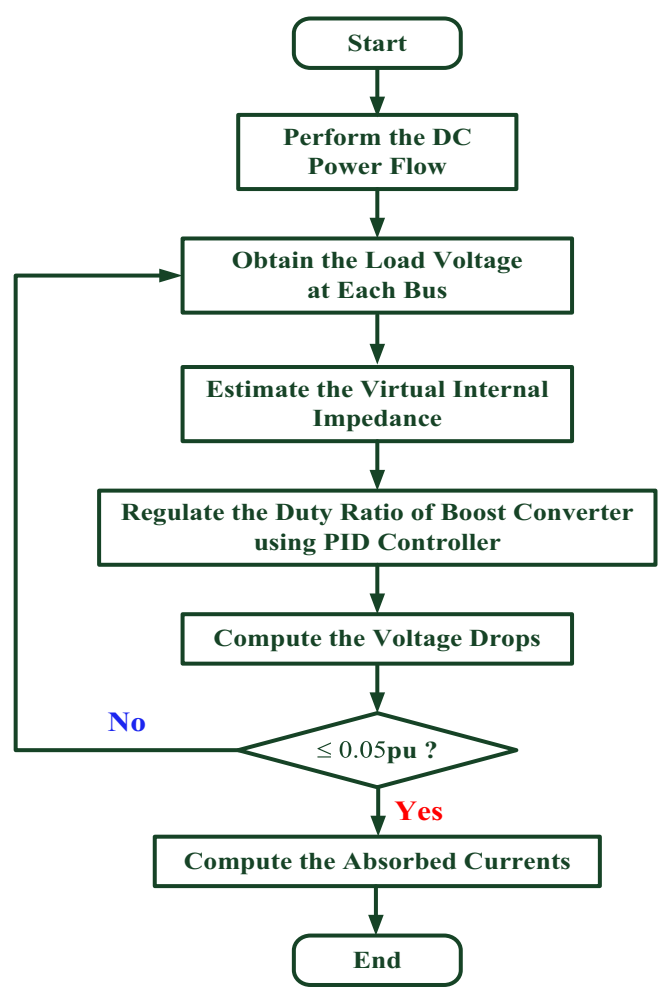

Fig. 6 The flow chart of voltage dependent DR for electronic loads process, the load voltage levels could be raised the specified range, $>0.95 \mathrm{pu}$, using the PID controller. Then, the internal load impedance of loads, $1 \#$ to $3 \#$, increased to reduce the absorbed currents of loads, as seen in Fig. $8 \mathrm{~b}$ and c. The final duty ratios of loads, $1 \#$ to $3 \#$, were $0.5524,0.5417$, and 0.5417 , respectively.

When a DC microgrid operated in a stand-alone mode, DG sources could completely supply local loads without main grid connection. However, renewable energy sources were variable because of environmental conditions. Hence, energy storage devices were used to provide backup capacity for the microgrid and to enhance the system stability and reliability. When DG resources was greater than the local load demand, extra energy would charged into batteries. In the other hand, when DG resources were less than load demand, then energy storage would be discharged. Then, the proposed virtual internal impedance screening model acted to identify the heavy loads. The PID controllers also acted to modify the absorbed currents from the DG sources, or non-priority load (such as Load 6\#) needed be disconnected to keep the power supply continued for controllable power electronic loads. The feasibility of virtual internal impedance screening was validated through simulation tests.
Fig. 7 The experimental results for MPPT. a The results of PV array power versus $\mathrm{PV}$ array voltage $(\mathrm{P}-\mathrm{V}), \mathbf{b}$ The results of $\mathrm{PV}$ array current versus $\mathrm{PV}$ array voltage (I-V), $\mathbf{c}$ The results of duty ratio versus switch number (a)
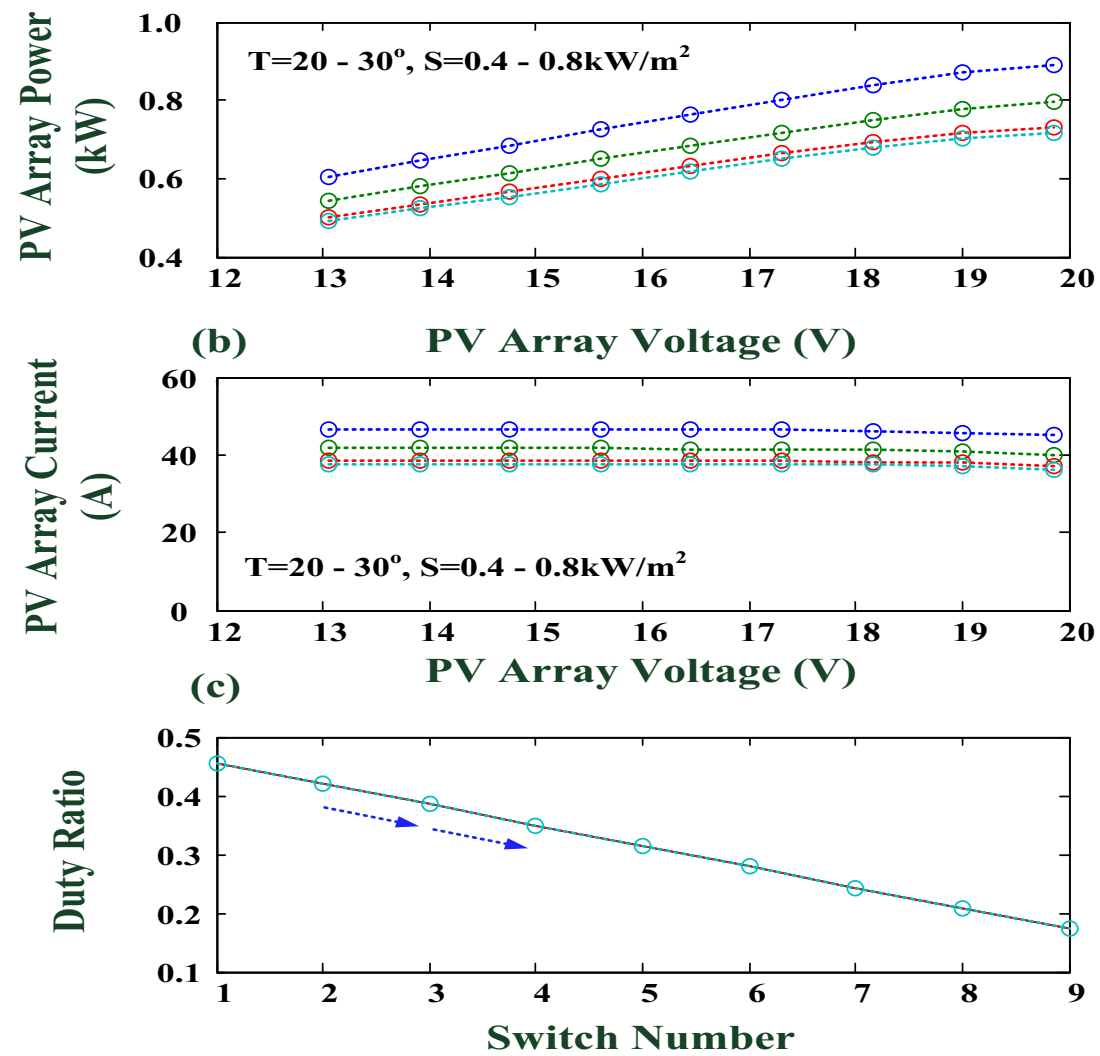
(a)

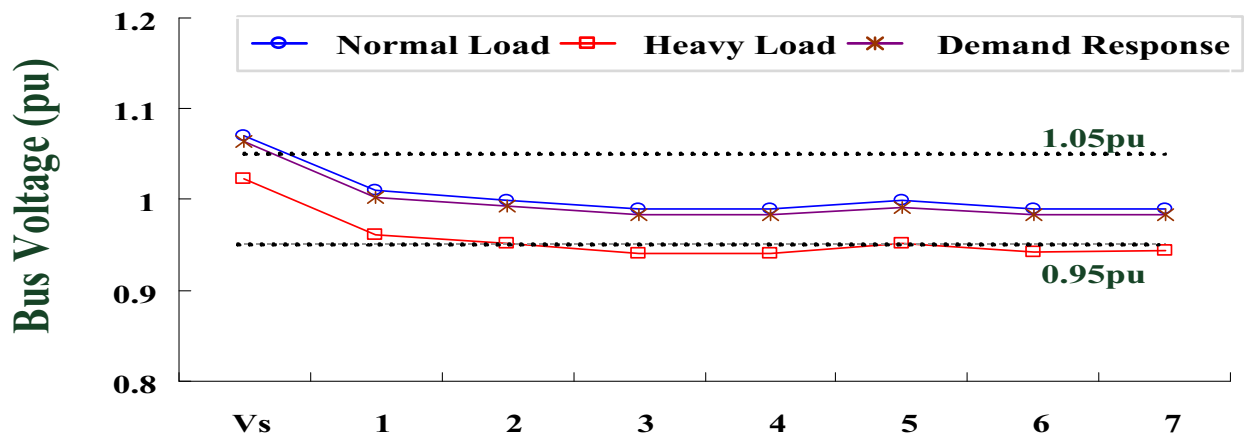

(b)

Bus Number

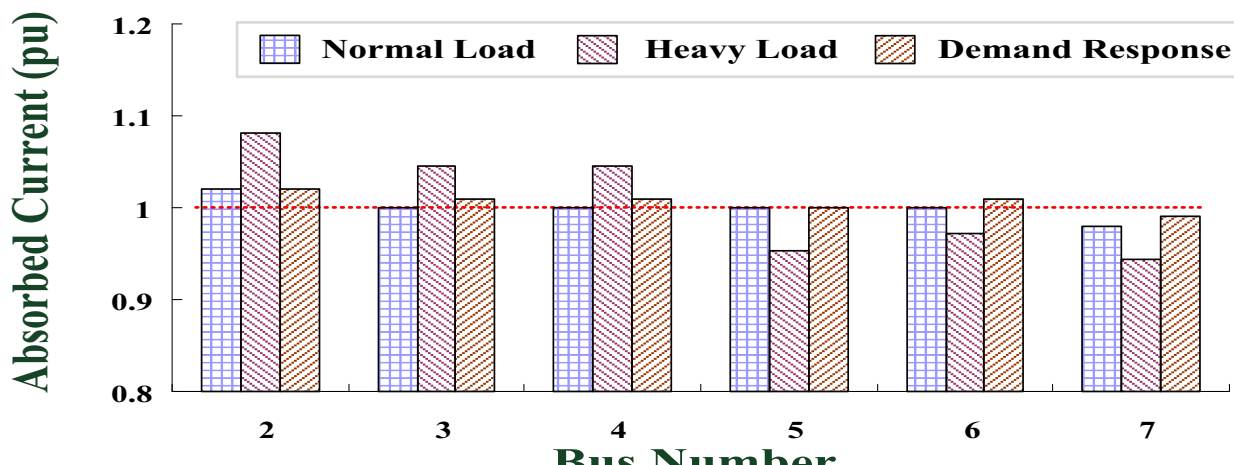

(c)

Bus Number

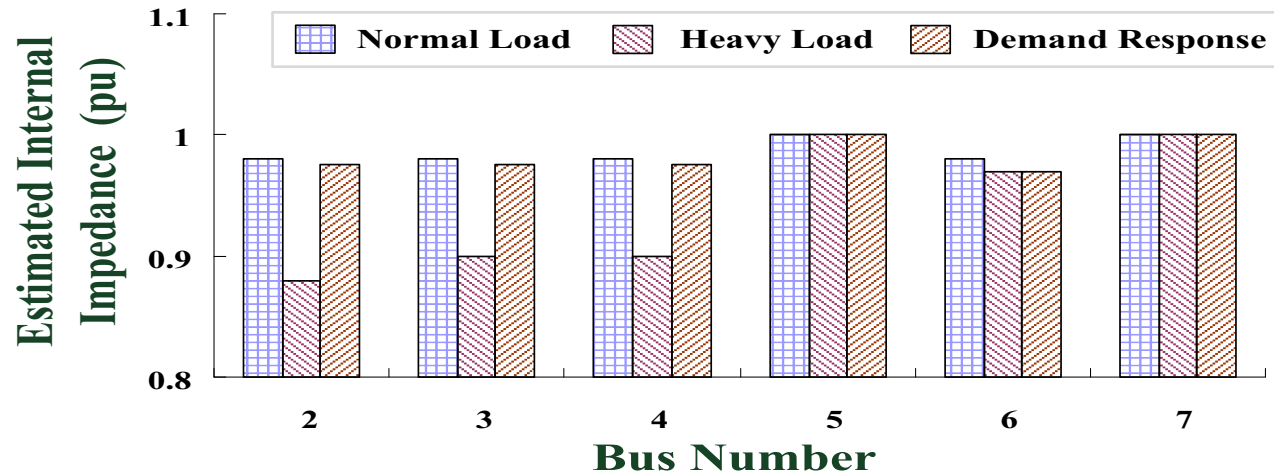

Fig. 8 Bus voltages (pu), absorbed currents (pu), and internal impedances (pu) in the dc microgrid. a Bus voltage distributions, b Absorbed current distributions, c Estimated internal impedances

\section{The Results of Voltage Dependent DRs for Electronic Loads}

According to the changes in the virtual internal load impedances, power electronic loads $1 \#$ to $3 \#$ had large deviations to regulate the duty ratios of boost converters. The procedure of DR for the power electronic loads was

Step 1) estimate the deviations in duty ratio using the Eq. 24,

Step 2) compute the desired duty ratio using the Eq. 26,

Step 3) regulate the duty ratio using the PID controllers using Eq. 29. Simulation results are in Fig. 9a.
Therefore, the desired duty ratios of loads, $1 \#$ to $3 \#$, can be determined using Eq. 26, as 0.5524, 0.5417, and 0.5417 , respectively. In this study, PID and PI controllers with different control parameters were employed to regulate the duty ratios of the boost converters at busses, $2 \#$ to $4 \#$, as shown in Fig. 9b. For example, DR program for electronic load $1 \#$, the duty ratio regulation was used to step-up load voltages from 0.5000 (rated load voltage: 24VDC / 48VDC) to the desired duty ratio, 0.5524 . The load voltage, $2 \#$, could be modified within the critical range, $0.95-1.05$, in per-unit value. Without selecting suitable control parameters, it can be seen that the overshoot maximum percentage, $5.02 \%$, is within the PI control response $\left(K_{P}=0.50, K_{I}=0.60-\right.$ 
Fig. 9 The simulation results of voltage dependent DR. a Electronic load DRs; b Regulate the duty ratio using the PI controllers without the suitable control parameters; c Regulate the duty ratio using the PI controllers with the suitable control parameters (a)

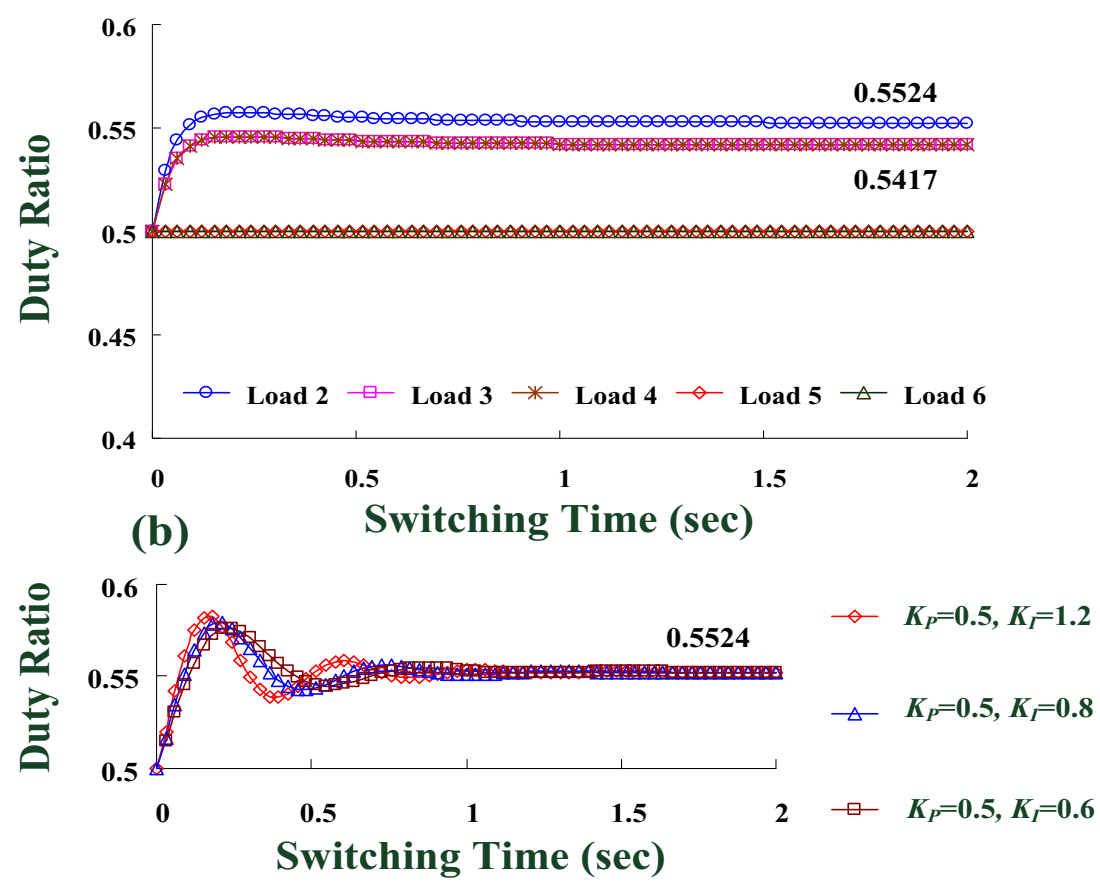

(c)

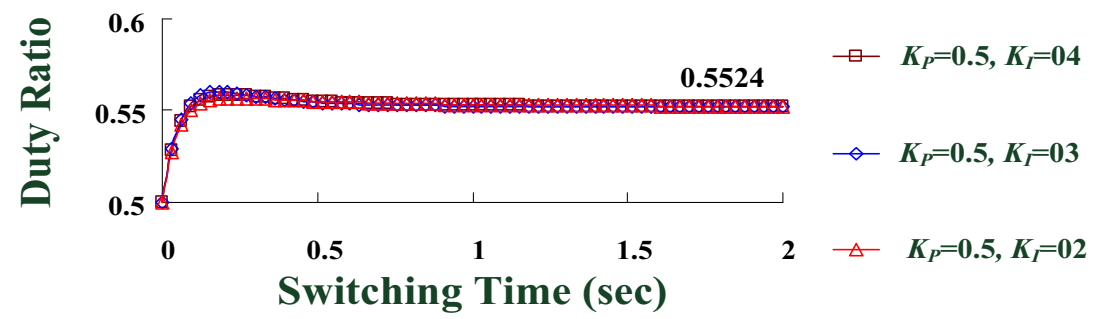

$-1.20, K_{D}=0.00$ ), Fig. 9b. In addition, the PID controller without selecting the suitable parameters has also larger overshoot $(>3.10 \%)$ and oscillation responses, resulting in increase the setting time $(>1.00 \mathrm{sec})$ to achieve the steady-state value. As seen in Table 1, the Ziegler-Nicholasbased tuning rule is used to tune the control parameters, and then the suitable control parameters can minimize the overshoot $(<1.6 \%)$, improve transient responses, and decrease steady-state errors to meet the desired operating point. For example, given the same initial conditions, the PI controller with control parameters, $K_{P}=0.50, K_{I}=0.20$ $-0.40, K_{D}=0.00$, decrease the overshoot, steady-state error, and settling time to $<1.00 \mathrm{sec}$ for reaching the steady-state value. It requires $<25$ switching cycles to reach the desired target and to achieve a $0.00 \%$ of steady-state error. Therefore, PI controller with suitable parameters can improve the transient responses and degrade the transientstate currents injection into the power electronic load. In addition, the transient larger currents surging into the DCDC converter during the transition power switching can also be avoided. The internal load impedance can be modified to improve the load voltage within the critical range of $0.95 \mathrm{pu}$ and $1.05 \mathrm{pu}$. As seen in Fig. 8a, after performing the direct load control for DR, overall bus voltages can be maintained in the specific normal range. The advantages of the proposed methods are summarized:

- the virtual internal load impedance can be estimated by off-line analysis using the DC power flow, and on-line analysis using the measurement data from smart meters in an AMI environment,

- the control parameters of the PID or PI controller can be easily determined with the Ziegler-Nicholas-based tuning rule,

- the exact load voltages can be accurately regulated in the specific range at both the power source and load sides.

We provide a promising method for changing the internal impedance of power electronic loads, then controlling the power flow from the DC power source to each load in the 
DR strategy. The feasibility of the proposed methods has been validated.

\section{Conclusion}

Voltage dependent DR with a virtual internal impedance model and a PID Controller was established in a DC microgrid. A virtual impedance model was used to estimate the internal impedance changes in power electronic loads. According to the internal impedance changes, the desired duty ratio could be determined. Based on direct load control, the PID or PI controller regulated the boost converter to change the internal impedances, and reduced the heavy loads with the voltage-mode boost converter operating in continuous conduction mode. Through the boost converter, the absorbed currents could be regulated from the DG source to each load side during peak hours. Hence, bus voltages, line voltage drops, and power losses were improved. For a DC microgrid, simulation results showed the feasibility of the proposed procedure for a DR program. In this study, DC power flow analysis was used to validate the results: (1) virtual impedance screening and (2) voltage dependent DRs for power electronic loads.

The simulation results confirmed that the proposed methods can be extended to a real smart microgrid. They ensure stable operation, keeping the bus voltages and power flow running flexibly within the limits for energy management applications. Under an AMI environment, the proposed methods could be further embedded into the existing MDM system, which gather voltage, current, and power from the whole DC microgrid. Metering data and bidirectional communication support the on-line applications in small- or large-scale microgrids. Thus, the proposed virtual impedance screening model has the capability to estimate the changes in internal impedances and duty ratios. Based on direct load control, the tuned PID controller can rapidly regulate the absorbed currents. In addition, the proposed methods can be easily implemented in an embedded system, a pc-based monitor, or an intelligent I a smart meter. Based on cloud computing, the wire / wireless communication technique is used to connect a network including one or more meters and a MDM system, which transmits metering data for identifying the heavy loads. Based on direct load control mode, the proposed methods and cloud computing can be integrated to control the heavy loads to keep the power supply continued for controllable loads during peak hours. With its feasibility evaluations, this technology support indicates that the proposed models can be easily implemented with inexpensive software and an embedded design device.
Acknowledgments This work is supported in part by the Ministry of Science and Technology (MOST), Taiwan, under contract number: MOST 104-2221-E-244-010 and MOST 105-2221-E-244010, duration: August 12015 October 312017.

\section{References}

1. Dragicevic T, Lu X, Vasquez JC, Guerrero JM (2015) DC microgrids-Part I: a review of control strategies and stabilization techniques. IEEE Trans Power Electron 31(7):4876-4891

2. Dragicevic T, Lu X, Vasquez JC, Guerrero JM (2015) DC microgrids-Part II: a review of power architectures, applications, and standardization issues. IEEE Trans Power Electron 31(5):3528-3549

3. Che L, Shahidehpour M (2014) DC microgrid: economic operation and enhancement of resilience by hierarchical control. IEEE Trans Smart Grid 5(5):2517-2526

4. Reddy KS, Kumar M, Mallick TK, Sharon H, Lokeswaran S (2014) A review of integration, control, communication and metering of renewable energy based smart grid. Renew Sustain Energy Rev 38:180-192

5. Chauhan RK, Phurailatpam C, Rajpurohit BS, Gonzalez-Longatt FM, Singh SN (2017) Demand-side management system for autonomous DC microgrid for building. Technol Econ Smart Grids Sustain Energy 2:4

6. Pacific Gas and Electric Company, Aggregator Programs, Demand Response Fact sheet (2013)

7. Rodriguez-Molina J, Martinez-Nunez M, Martinez J-F, PerezAguiar W (2014) Business models in the smart grid: challenges, opportunities and proposals for prosumer profitability. Energies 7:6142-6171

8. Gulich O (2010) Technological and business challenges of smart grids-aggregator's role in current electricity market. Master's thesis, Lappeenranta University of Technology Faculty of Technology and Electrical Engineering

9. Lu N (2012) An evaluation of the HVAC load potential for providing load balancing services. IEEE Trans Smart Grid 3(3):1263-1270

10. Wang Z, Paranjape R, Sadanand A, Chen Z (2013) Resiential demand response: an overview of recent simulation and modeling applications. In: The 26th annual IEEE Canadian conference on electrical and computer engineering, pp 1-6

11. Chang L-Y, Chung Y, Chen S-J, Kuo C-L, Lin C-H (2016) Demand response and ancillary service management using fractional-order integral indicator and dynamic game model for an aggregator program in smart grids. Technol Econ Smart Grids Sustain Energy 1(16):1-12

12. Weaver W (2011) Dynamic energy resource control of power electronics in local area power networks. IEEE Trans Power Electron 26(3):852-859

13. Kazemlou S, Mehraeen S, Saberi H, Jagannathan S (2017) Stability of the small-scale interconnected DC grids via outputfeedback control. IEEE J Emerg Sel Top Power Electron 5(3):960970

14. Negri S, Tironi E, Danna DS (2017) Integrated control strategy for island operation in smart grids: virtual inertia and ancillary services. In: 2017 international conference on environment and electrical engineering and 2017 IEEE industrial and commercial power system Europe, pp 1-6

15. Nguyen K-L, Won D-J, Ahn S-J, Chung I-Y (2012) Power sharing method for a grid connected microgrid with multiple distributed generators. J Electr Eng Technol 17(4):459-467 
16. Basic H, Dragicevic T, Pandzic H, Blaabjerg F (2017) DC microgrids with energy storage systems and demand response for providing support to frequency regulation of electrical power systems. In: 2017 19th European conference on power electronics and applications

17. Mohsenian-Rad H, Davoudi A (2014) Towards building an optimal demand response framework for dc distribution networks. IEEE Trans Smart Grid 5(5):2626-2634

18. Mackay L, Kolios P, Ramirez-Elizondo L, Bauer P (2015) Voltage dependnt demand response with dynamic hysteresis thresholds in DC microgrids. In: 2015 IEEE Eindhoven power tech

19. Ramirez-Fonseca I, Mackay L, Van der Blij NH, Hailu Tg, Ramirez-Elizondo L, Bauer P (2016) Impact of voltage dependent demand response on the dynamic of DC microgrids. In: International conference on sustainable green building and communities

20. Nasir M, Khan HA (2016) Solar photovoltaic integrated building scale hybrid AC/DC microgrid. In: 2016 5th IET international conference on renewable power generation, pp 1-6

21. Pavan Kumar YV, Bhimasingu R (2016) Performance analysis of static versus rotary DC/AC power converter for hybrid renewable energy based microgrid applications. In: 2016 IEEE Region 10 conference, pp 1456-1461

22. Mohamed A, Mohammed O (2010) Power flow control in dc distribution systems. In: Proceedings of the IEEE NAPS. Arlington, pp 1-7

23. Mohsenian-Rad H, Davoudi A (2013) Optimal demand response in dc distribution network. In: IEEE international conference on smart grid communication. Vancouver, pp 564-569

24. Maknouninejad A, Qu Z, Lewis FL, Davoudi A (2014) Optimal, nonlinear, and distributed designs of droop controls for DC microgrids. IEEE Trans Smart Grid 5(5):2508-2516

25. Glover D, Sarma M Power system analysis and design. PWS Publishing Company, Boston. ISBN0-53493-960-0

26. Brown HE (1975) Solution of large network by matrix methods. Wiley, New York

27. Ma Y, Karady GG (2009) Investigating grounding grid integrity based on the current injection method. In: 2009 North American power symposium, pp 1-5

28. Kuo C-L (2007) Design of an adaptive Fuzzy sliding-mode controller for chaos synchronization. Int J Nonlinear Sci Numer Simul 8(4):631-636
29. Meza JL, Santibaenz V, Soto R, Llama MA (2012) Fuzzy self tuning PID semi global regulator for robot manipulators. IEEE Trans Ind Electron 59:2391-2401

30. Singhal R, Padhee S, Kaur G (2012) Design of fractional order PID controller for speed control of dc motor. Int J Sci Res Publ 2(6): $1-8$

31. Ziegler JG, Nichols NB (1942) Optimum settings for automatic controllers. Trans ASME 64:759-768

32. Singhal R, Padhee S, Kaur G (2012) Design of fractional order PID controller for speed control of dc motor. Int J Sci Res Publ 2(6): $1-8$

33. Chen GY, Perng JW, Ma L-S (2015) DSP based BLD motor controller design with auto tuning PSO-PID algorithm. In: 2015 IEEE/SICE international symposium on system integration

34. Arulmozhiyal R (2012) Design and implementation of fuzzy PID controller for BLDC motor using FPGA. In: 2012 international conference on power electronics, drives and energy systems

35. Kuo C-L, Lin C-H, Yau H-T, Chen J-L (2013) Using selfsynchronization error dynamics formulation based controller for maximum photovoltaic power tracking in micro-grid systems. IEEE J Emerg Sel Top Circ Syst 3(3):459-467

36. Kuo C-L, Chen J-L, Chen S-J, Kao C-C, Yau H-T, Lin CH (2017) Photovoltaic energy conversion system fault detection using fractional-order color relation classifier in microdistribution systems. IEEE Trans Smart Grid 8(3):1162-1172

37. Wang Z, Paranjape R, Sadanand A, Chen Z (2013) Resiential demand response: an overview of recent simulation and modeling applications. In: 26th annual IEEE Canadian conference on electrical and computer engineering, pp 1-6

38. Brusco G, Burgio A, Menniti D, Pinnarelli A, Sorrentino N (2014) Energy management for an energy district with demand response availability. IEEE Trans Smart Grid 5(5):2385-22393

39. Chen J-L, Kuo C-L, Chen S-J, Kao C-C, Zhan T-S, Lin CH, Chen Y-S (2016) DC-side fault detection for photovoltaic energy conversion system using fractional-order order dynamic error based fuzzy petri net integrating with intelligent meters. IET-Renew Power Gener 10(9):1318-1329

40. Marasco K (2011) How to apply dc-to-dc step-up (boost) regulator successfully, Analog Dialogue 45-09 Back Burner, pp 1-3. www. analog.com/analogdialogue 